\title{
ARTÍCULO
}

\section{Las características formales de la ley humana en Juan de Mariana`}

\section{The formal characteristics of human law in Juan de Mariana}

\author{
Fernando Centenera Sánchez-Seco \\ Área de Filosofía del Derecho \\ Universidad de Alcalá (Madrid)
}

Fecha de recepción 22/01/2018 | De aceptación: 06/06/2018 | De publicación: 27/06/2018

\section{RESUMEN.}

Este trabajo centra la atención en las características formales de la ley humana en el pensamiento de Juan de Mariana. En él se ofrece una presentación general de aquellas, acompañada de algunas circunstancias de la época. A continuación se trata de determinar la intención del autor en sus desarrollos y se analizan sus aportaciones, tanto desde la perspectiva del pensamiento ilustrado como desde el iusfilosófico de nuestro tiempo. Todo ello evidencia puntos de encuentro, pero también diferencias relevantes. El estudio repara además en la aportación de los aspectos considerados en los ámbitos de la limitación al poder y la justicia.

\section{PALABRAS CLAVE.}

Mariana, ley, carácter general, claridad, brevedad

\section{ABSTRACT.}

This article considers the formal characteristics of human law in the thought of Juan de Mariana. After a general introduction to those characteristics, accompanied by some contextual background, an attempt is made to ascertain the author's intentions as his thought developed and to analyse his particular contribution to the matter through the double optic of enlightenment thought on the one hand, and contemporary jusphilosophy on the other. Some points of connection are found, but also various significant differences. At the same time, the article also gives some thought to the contribution made by the various aspects under consideration in the fields of justice and of the restriction of power.

KEY WORDS.

Mariana, law, generality, clarity, brevity

\footnotetext{
- Trabajo desarrollado en el marco del Proyecto $\mathrm{I}+\mathrm{D}+\mathrm{i}$ "Pensamiento y tradición jesuita y su influencia en la modernidad desde las perspectivas de la historia, la traductología y la filosofía jurídica, moral y política”. La referencia del proyecto es: FFI2015-64451-R (MINECO/FEDER). Quisiera agradecer los comentarios de quienes realizaron los exámenes del trabajo.
} 
Índice: Introducción 2. El planteamiento general de las características y su época, 3. Los posibles sentidos de los planteamientos, 4. Algunas consideraciones con la mirada en la Ilustración, 5. Algunas consideraciones desde nuestro tiempo, 6. La contribución a la limitación del poder, 7. La contribución a la justicia, 8 . Bibliografía

\section{Introducción}

Juan de Mariana no es un autor desconocido en el ámbito de la investigación. Su obra ha llamado y llama la atención de buen número de estudios procedentes de diferentes áreas de conocimiento, que llegan hasta la época más reciente. Tal circunstancia quizá pudiera dar lugar a pensar que en nuestro tiempo, la elaboración de trabajos sobre el jesuita conduce irremediablemente a lugares comunes. Sin embargo, no necesariamente ha de ser así, pues, entre otras cosas, al menos en determinadas materias no toda la documentación del autor está publicada, no existe un criterio de interpretación uniforme de su pensamiento, ni tampoco se han explorado a fondo algunas de sus ideas. Probablemente circunstancias como estas impulsen varias aportaciones en el futuro próximo, motivadas también por el cumplimiento de los cuatrocientos años de la muerte del autor (en 1624).

Este estudio centra la atención en una temática que, al menos hasta donde conocemos, no ha recibido una atención detenida. Nuestra intención es considerar las características formales de la ley humana en el pensamiento del jesuita. No se trata de una cuestión que juegue un papel protagonista en sus obras, pero ello entendemos que no obsta para plantear un estudio en la línea expuesta. En las siguientes páginas tratamos de demostrarlo, teniendo en cuenta para ello los siguientes trabajos del autor: De rege et regis institutione (en delante De rege), Discurso de las enfermedades de la Compañía (en adelante Discurso) ${ }^{1}$ y de forma puntual también el Tratado y discurso sobre la moneda de vellón (en adelante Tratado).

Para llevar a cabo la labor anunciada hemos optado por el siguiente esquema. En primer lugar presentamos una descripción general de las características en cuestión, acompañada de algunos detalles de la época que pueden ayudar a comprender el desarrollo de algunas de ellas. A continuación, tratamos de determinar las intenciones del autor con sus propuestas, para después considerarlas desde la perspectiva de la Ilustración y desde las aportaciones iusfilosóficas de nuestro tiempo ${ }^{2}$. El trabajo concluye con un

\footnotetext{
${ }^{1}$ Aunque el autor dedica esta obra a su Orden, en buen número de sus planteamientos sobre el gobierno y las leyes traslada al contexto citado lo que dice desde un punto de vista general en el De rege, incluso en determinados aspectos de forma más pormenorizada.

${ }^{2}$ Análisis de este tipo se han llevado a cabo con respecto a trabajos coetáneos a Mariana. Por nuestra parte, recientemente hemos publicado la siguiente referencia: CENTENERA SÁNCHEZSECO, F.; "El lenguaje de la ley humana en el pensamiento de Francisco Suárez", Pensamiento. Revista de Investigación e Información Filosófica, 74/279, 2018, pp. 123-145,
} 
espacio dedicado a la función que cumplen las características con respecto a la limitación del poder, y otro relativo a su aportación a la justicia.

\section{El planteamiento general de las}

\section{características y su época}

Mariana no dedica un apartado exclusivo a las características formales de la ley, aunque las trata a propósito de varios temas. Así acontece en el De rege, donde tras considerar la situación anómica de los primeros tiempos, descubre el motivo que, según él, impulsó la aparición de las leyes escritas: las sospechas sobre la equidad de quien gobernaba, que difícilmente miraba a las demás personas de la misma forma y era incapaz de aislarse de sus odios. Por ello se promulgaron "leyes que tuviesen siempre el mismo sentido para todos"3. Poco después, tras plantear una definición de ley que más adelante nos ocupará, el autor se refiere a la concisión y claridad de aquella, señalando que dichas características estuvieron presentes en un primer momento, cuando no era necesario comentario alguno de las

http://revistas.upcomillas.es/index.php/pensamiento/article/view/8 789/8302. Sin embargo, al menos por lo que conocemos, tal circunstancia no ha tenido lugar a propósito del jesuita. En este trabajo pueden verse algunos puntos de conexión con el recientemente citado, principalmente en lo que respecta al ámbito lingüístico. Quisiéramos señalar además que varias de las características que aquí consideramos nos han ocupado en otros estudios, aunque no a propósito de Mariana.

3 DE MARIANA, J.; La dignidad real y la educación del rey, Sánchez Agesta, L. (trad.), Madrid, Centro de Estudios Constitucionales, 1981, p. 27. leyes. Sin embargo, prosigue Mariana, después, y de nuevo a consecuencia de la maldad de las personas, las leyes se multiplicaron hasta el punto de preocupar más que los vicios que reprimían. La desolación del jesuita se prolonga, cuando señala que sería incluso insuficiente "el trabajo de Hércules para limpiar los establos de leguleyos"4. La intensidad de tal apreciación queda patente si recurrimos al relato mitológico que, según interpretamos, Mariana debió tener en mente al escribir sus palabras; concretamente, el quinto trabajo de Hércules, que consistió en limpiar de estiércol los establos del rey Augías ${ }^{5}$.

Los aspectos anteriores se reiteran más adelante, cuando de nuevo Mariana señala que las leyes nacieron para evitar afectos como el odio, la ira o el amor, que perturban la justicia. Por ello, se establecieron con carácter general, para vetar el paso a las pasiones ${ }^{6}$. Más adelante, el autor abunda en la promulgación legislativa, señalando que con ella se establecen las leyes, que se aprueban cuando "se confirman por las costumbres del pueblo"7. Por otra parte, también

${ }^{4}$ DE MARIANA, J.; La dignidad real..., p. 27. Resulta interesante constatar que, según Erasmo, la última palabra remitía a un colectivo que regulaba con sus decisiones las actividades de las personas, obteniendo importantes beneficios. DE ROTTERDAM, E.; Elogio de la estupidez, Fanego Pérez, T. (ed.), Madrid, Akal, 2004, p. 146.

5 Hemos consultado el relato en APOLODORO; Biblioteca Mitológica, García Moreno, J. (trad.), Madrid, Alianza Editorial, segunda reimpresión, 2013, pp. 103, 104.

${ }^{6}$ DE MARIANA, J.; La dignidad real ..., p. 32.

${ }^{7}$ Ibídem, p. 95. 
constata, siquiera indirectamente, la conveniencia de la estabilidad legislativa con estas palabras: "las sacrosantas leyes en que descansa el bienestar público serán sólo estables si las sanciona él mismo [quien gobierna] con su ejemplo"8.

Avanzada la obra, en el capítulo dedicado a los juicios el autor de nuevo se refiere a la arbitrariedad en la aplicación de las leyes, y pensamos que también implícitamente a la necesidad de que aquellas sean generales, para así evitar una aplicación desigual ${ }^{9}$. En el mismo contexto denuncia la prolijidad y dificultad para comprender las leyes. Además, recomienda la derogación de muchas de ellas, pues de otra manera su complimiento resulta difícil. De este modo, según el autor únicamente deberían quedar las necesarias, que pudieran entender todas las personas ${ }^{10}$. En lo que respecta a los obstáculos que impiden la correcta compresión del texto, Mariana se refiere concretamente a la ambigüedad, que da lugar a que se pueda eludir la ley por medio de interpretaciones ${ }^{11}$. Conviene

\footnotetext{
${ }^{8}$ Ibídem, p. 107.

${ }^{9}$ Ibídem, p. 371.

${ }^{10}$ La traducción de Sánchez Agesta, recogida en la edición del De rege que utilizamos principalmente, hace referencia a la comprensión de las leyes por las personas de "mediano ingenio", y poco después a leyes "al alcance de todas las inteligencias". DE MARIANA, J.; La dignidad real..., p. 373.

11 En este punto el sentido del texto cambia, si se acepta la interpretación del original que muestra aquí el problema de eludir mediante interpretación lo que está claro en la ley. DE MARIANA, J.; "Del rey y de la institución real", en Pi y Margall, F. (ed.), Obras del padre Juan de Mariana, Madrid, M.
}

recordar que en esta ocasión las apreciaciones se contextualizan en el ámbito judicial, y que a propósito del mismo, poco antes de abordar los aspectos anteriores, el jesuita señala que quienes imparten justicia no han de recurrir a agudezas para "retorcer la ley a su capricho, separándola de su verdadero sentido para fallar en favor de aquellos a quienes no ampara el derecho ni la equidad"12.

Mariana considera también algunas de las características citadas en el Discurso, donde incluso dedica un capítulo a las leyes. En esta obra se refiere a la gran cantidad de aquellas en la Compañía y también a las consecuencias que ello suscitaba: que el General no se gobernase conforme a las leyes, pues no era posible cumplir todas, y que se las perdiera el respeto ${ }^{13}$. En la misma obra el autor también se refiere a la brevedad, a los inconvenientes de la precisión (que más adelante consideraremos con más detalle) y a los cambios frecuentes en las leyes, que van en detrimento de la autoridad que aporta la antigüedad y el uso en el cumplimiento ${ }^{14}$.

Rivadeneyra, 1854, p. 555 . En esta interpretación la oscuridad de las leyes, al menos en parte, se presenta como resultado de las interpretaciones.

${ }^{12}$ DE MARIANA, J.; La dignidad real..., p. 373.

13 DE MARIANA, J.; Discurso de las enfermedades de la Compañia, Madrid, Imprenta de D. Gabriel Ramirez, 1768, pp. 152,156 y 216 y ss.

${ }^{14}$ Ibídem, p. 217. 
A nuestro modo de ver, con las apreciaciones anteriores Mariana participa del discurso clásico sobre las características formales de la 1 ley ${ }^{15}$, que probablemente debió considerar sugestivo a la luz de las circunstancias de su época. Con ello comparte preocupaciones de contemporáneos como Pedraça que, por ejemplo, también se haría eco del ingente número de leyes o su prolijidad ${ }^{16}$; o Suárez, en cuya obra encontramos las recomendaciones de claridad, brevedad y sencille ${ }^{17}$. Estas manifestaciones cobran sentido si tenemos en cuenta el contexto temporal en el que se enmarcan. Las consideraciones de Mariana sobre la ley probablemente enlacen con el interés que aquella suscitó desde el siglo XII. Entonces la actividad legislativa se incrementó y, con ello, la constatación de la ley como "norma establecida" frente al derecho consuetudinario ${ }^{18}$ que, no obstante, siguió teniendo un protagonismo indudable. Más concretamente, las objeciones del autor se entienden mejor a la luz de los siguientes detalles. Por una parte, en su época nos

\footnotetext{
${ }^{15}$ Por ejemplo, en la siguiente obra se considera el carácter general de las leyes, la fuerza que adquieren con el uso o las inconveniencias de la inestabilidad: ARISTÓTELES; Política, Marías, J. y Araujo, M. (trad.), Madrid, Centro de Estudios Constitucionales, 2. a edición, 1989, pp. 50, 51, 103.

16 BERMUDEZ DE PEDRAÇA, F.; Arte legal para estvdiar la Ivrisprvdencia, Salamanca, Emprenta de Antonia Ramirez, 1612, pp. 116, 145.

${ }^{17}$ SUÁREZ, F.; Tratado de las leyes y de Dios Legislador, vol. II, Eguillor Muniozguren, J. R. (trad.), Madrid, Instituto de Estudios Políticos, 1967, p. 256.

18 GARCÍA-GALlO, A.; Manual de Historia del Derecho Español, vol. I, Madrid, Artes Gráficas y Ediciones S. A., 9 edición, 1982, p. 220.
}

encontramos con el Derecho común, integrado por Derecho romano, Derecho canónico, Derecho feudal, instituciones del Derecho medieval e instituciones de los derechos $\operatorname{propios}^{19}$. Esta relación muestra, de entrada, un volumen importante de regulaciones, al que deberíamos añadir los derechos propios; si bien, como señalamos, en parte se incorporaban al Derecho común.

Una mirada más pormenorizada descubre además que las regulaciones del momento no se caracterizaban por su brevedad, al menos en buen número de casos. Podemos, por ejemplo, referirnos a las ordenanzas, que eran textos muy extensos dedicados a la regulación de diferentes cuestiones, por lo general de una institución. Aquellas aparecieron también a consecuencia de la recopilación de ordenanzas anteriores, y este proceso dio lugar a redacciones cada vez más amplias, hasta el punto de que algunas disposiciones de aquel tipo llegaron a tener más de trescientos capítulos ${ }^{20}$. Debemos considerar también las regulaciones derivadas del descubrimiento de América. Las Leyes Nuevas son paradigmáticas al respecto, pero también las reales instrucciones y cédulas que, por ejemplo, llegaron para moderar y precisar las tasaciones

\footnotetext{
19 PÉREZ MARTÍN, A.; "El Ius commune: artificio de juristas", en De Montagut, T. (ed.), Història del pensament jurídic, Barcelona, Universitat Pompeu Fabra, 1999, pp. 74 y ss.

${ }^{20}$ GARCÍA-GALLO, A.; op. cit., p. 225.
} 
tributarias confusas establecidas hasta el momento $^{21}$.

Además de todo lo anterior, hemos de tener también en cuenta la incorporación de nuevas normas que no coincidían con las recogidas en las compilaciones romanas o canónicas originales. Nos referimos a las surgidas de las opiniones procedentes de sentencias de tribunales superiores, o bien del ámbito doctrinal ${ }^{22}$. En la época, la interpretación de las leyes con opiniones de autoridades fue objeto de crítica, pues imprimía inestabilidad en la jurisprudencia, dado que los pareceres eran cambiantes y presentaban diversas formas de entender las leyes que, recogidas en volúmenes copiosos, quedaban desposeídas de su razón de $\operatorname{ser}^{23}$. El panorama resultante de todo aquello eran leyes dudosas, pues lo claro, cuando tenía lugar, con sutilezas se convertía en oscuro con perjuicio además para la justicia $^{24}$. Circunstancias como estas fundamentaban el rechazo que producían aquellas personas a las que Mariana se refiere con la palabra 'leguleyos'25, y probablemente también, al menos en parte, la jurisprudencia confusa del

\footnotetext{
${ }^{21}$ SARABIA VIEJO, M. J.; Don Luis de Velasco virrey de Nueva España. 1550-1564, Sevilla, Escuela de Estudios HispanoAmericanos, 1978, p. 327.

${ }^{22}$ MARCILlA CÓRDOBA, G.; Racionalidad legislativa. Crisis de la ley y nueva ciencia de la legislación, Madrid, Centro de Estudios Políticos y Constitucionales, 2005, p. 57.

${ }^{23}$ BERMUDEZ DE PEDRAÇA, F.; op. cit., p. 129.

${ }^{24}$ GARCÍA-GALLO, A.; op. cit., p. 230.

${ }^{25}$ Ibídem.
}

\section{Los posibles sentidos de los planteamientos}

A nuestro modo de ver, los planteamientos del jesuita sobre las cuestiones que nos ocupan pueden analizarse desde diferentes puntos de vista. Por una parte, nos encontramos con la constatación de diferentes circunstancias y problemas de la realidad jurídica del momento, detrás de la cual, a los ojos del autor, subyace

${ }^{26}$ Sobre ello ZAPATERO, V.; "Edición y estudio preliminar", en J. Bentham, J.; Nomografía o el arte de redactar leyes, Madrid, Centro de Estudios Políticos y Constitucionales, 2004, p. XXI.

${ }^{27}$ EZQUERRA REVILLA, I. J.; Justicia y gobierno en el siglo XVI. El Consejo Real de Castilla durante el reinado de Felipe II (1556-1598), Tesis Doctoral, Madrid, Universidad Autónoma de Madrid, 1999, p. 346, https://repositorio.uam.es/handle/10486/2583.

28 PINO ABAD, M.; Persecución y castigo de la exportación ilegal de bienes en Castilla (siglos XIII-XVIII), Madrid, Dykinson, 2014, p. 165. Una manifestación parecida aparece en unas advertencias dirigidas al presidente del Consejo Real, que constatan la importancia de guardar las leyes, más que hacer muchas y nuevas, habida cuenta de los inconvenientes que surgen de ello. EZQUERRA REVILLA, I. J.; op. cit., p. 174. Sobre otras advertencias véase ORTEGO GIL, P.; "El arbitrio de los jueces inferiores: su alcance y limitaciones", en Sánchez-Arcilla Bernal, J. (inv. principal), El arbitrio judicial en el Antiguo Régimen (España e Indias, siglos XVI-XVIII), Madrid, Dykinson, 2012, p. 140. 
como motivo la maldad de las personas. Esta fue la causa de la promulgación de las leyes, de su carácter general, pero también de su prolijidad y oscuridad constatable en la época que, a su vez, favorecían nuevamente la aparición de la maldad en sede judicial, especificada en el interés propio de quienes juzgaban ${ }^{29}$. En parte, este planteamiento muestra a un autor resignado con su realidad, que ve inalcanzable la situación de los primeros tiempos, y que incluso considera insuficiente el trabajo de Hércules para acabar con la mala práctica del derecho. La opción en este caso es reconocer la necesidad de las leyes y tratar de trabajar con las circunstancias que ofrece el orden jurídico, evitando prácticas abusivas. El propio jesuita ofrece muestra de ello en parte de su actividad intelectual, por ejemplo, en las argumentaciones que presenta en su Tratado, sobre la imposibilidad de imponer pechos y bajar la moneda de valor por parte de quien gobierna. En esta cuestión cita la ley otorgada por Alfonso XII en las Cortes de $1329^{30}$ y también, quizá siguiendo los criterios de doctrina común o sin contradicción ${ }^{31}$, recurre a comentaristas como el

\footnotetext{
${ }^{29}$ Esta idea puede localizarse en otros lugares del De rege. Así, en DE MARIANA, J.; La dignidad real..., p. 374. Sin embargo, ello contrasta con la afirmación de que tras el reinado de Isabel y Fernando los juicios fueron íntegros y justos (p. 371 de la misma referencia).

30 DE MARIANA, J.; Tratado y discurso sobre la moneda de vellón, Madrid, Ministerio de Economía y Hacienda, 1987, pp. 3641.

${ }^{31}$ Sobre ello GARCÍA-GALLO, A.; op. cit., p. 231.
}

'Panormitano'32. Además, en el texto del proceso que sufrió a consecuencia de la obra citada reconoce entre sus fuentes a Covarrubias ${ }^{33}$.

El desarrollo anterior, que nos muestra a un autor resignado con la situación en la que vive y que participa intelectualmente del orden jurídico del momento, no impide apreciar en sus palabras cierto matiz crítico con respecto al mal uso de las leyes y los comentarios, si bien no desdeña a estos últimos per se. La palabra 'leguleyos' que utiliza es muy significativa, pues probablemente con ella se estuviera refiriendo al abuso en la interpretación. Sin embargo, cabría preguntarse si sus críticas se agotan en dicho detalle. No parece que sea así. A nuestro modo de ver, en sus planteamientos puede percibirse algo más que la mera constatación de una situación. Resulta interesante señalar que el relato sobre lo que probablemente aconteció en los primeros tiempos, se encuentra cercano ${ }^{34}$ a algunos de los que que

\footnotetext{
${ }^{32}$ Mariana probablemente está aludiendo a los comentarios de las Decretales del Abad Panormitano (el autor utiliza precisamente esta última denominación en DE MARIANA, J.; La dignidad real..., p. 291). Su fuente podría haber sido PANORMITANI, A.; Commentaria In Tertiam Secundi Decretalium Libri Partem, Venetiis, [s. ed.], MDLXXI, p. 202 (reverso).

33 Concretamente, se refiere al "lib. De veterum numismatum collatione; cap. VII, no 6". Proceso Fabricado a instancia de Dn Gilimon de la Mota, Fiscal [...] contra el Padre Juan de Mariana de la Compañia de Jesus, manuscrito, 1610, fol. 30 (reverso). Entendemos que se trata de la siguiente referencia: COUUARRUUIAS À LEYUA, D.; Vetervm Collatio Nvmismatvm, cum his, quae modò expenduntur, publica \& Regia authoritate percusa, Salmanticae, Excudebat Andreas à Portonarijs Typographus Regius, MDLXII, pp. 51, 52.

${ }^{34}$ Mariana estimaba a Moro, así lo confirman los informes que emitió sobre él. GARCÍA HERNÁN, E.; "Juan Luis Vives y Tomás Moro en la crisis religiosa del siglo XVI", en Betrán J. L., Hernández, B., Moreno, D. (eds.), Identidades y fronteras
} 
acompañan a las leyes de la Utopía de Tomás Moro $^{35}$. Merece la pena la comparación de los siguientes textos.

\begin{tabular}{|c|}
\hline Tomás Moro. Utopía \\
\hline $\begin{array}{l}\text { "Tienen muy pocas leyes, pues para un } \\
\text { pueblo así organizado son suficientes } \\
\text { poquísimas. Lo que primero censuran en } \\
\text { estos pueblos es que no les son suficientes } \\
\text { infinitos volúmenes de leyes y de } \\
\text { intérpretes" }\end{array}$ \\
\hline Juan de Mariana. De rege \\
\hline $\begin{array}{l}\text { "Es verosímil creer que en un principio } \\
\text { existieron poquísimas leyes y que éstas eran } \\
\text { concisas y claras, sin que necesitaran de } \\
\text { ningún comentario. Pero más tarde [...] } \\
\text { creció la multitud de las leyes" }\end{array}$ \\
\hline
\end{tabular}

Tabla 1. Comparación de textos de Tomás Moro y Juan de Mariana.

El interesante parecido que refleja esta tabla suscita la pregunta de si el planteamiento del jesuita participa de cierta dosis de utopía. Desde una perspectiva general la propuesta cobra sentido, si tenemos en cuenta que con la utopía se plantea la mejor forma de gobierno, y que ello no

culturales en el mundo ibérico en la Edad Moderna, Barcelona, Universitat Autònoma de Barcelona, 2016, pp. 279, 280.

35 MORO, T.; Utopía, García Estébanez, E. (trad.), Madrid, Tecnos, 1987, p. 101. queda lejos del esquema contextual que comprende las cuestiones que trata Mariana ${ }^{36}$. En función de la respuesta que demos a la cuestión, otorgaremos un mayor o menor espacio a la dimensión crítica de su planteamiento. Ciertamente, en lo que respecta al extracto transcrito la respuesta sería negativa, si interpretamos que en él se considera la ley natural $^{37}$; pues con ello estaríamos reconociendo una situación anómica, que no se ajusta a la literatura utópica ${ }^{38}$. No obstante, si se acepta que en este punto el jesuita se está refiriendo a leyes humanas $^{39}$, entendemos que la respuesta debería ser positiva, aunque con matices.

El autor parece considerar inalcanzable la situación de los primeros tiempos, pero también es cierto que no renuncia a avanzar en las cuestiones señaladas, y que además su apuesta apunta en ocasiones a un nivel alto en su

${ }^{36}$ Sobre la idea, en general, RAMIRO AVILÉS, M. A.; "Estudio introductorio", en Anónimo; Descripción de la Sinapia, península en la tierra austral, Madrid, Dykinson, 2013, p. 12.

${ }^{37}$ Sobre este punto de vista, por ejemplo, NAVARRO AZNAR, F.; "Trilogía de la ley en Juan de Mariana", en Bello, E. (ed.), Filosofía, sociedad e incomunicación. Homenaje a Antonio García Martínez, Murcia, Secretariado de Publicaciones. Universidad de Murcia, 1983, p. 323.

${ }^{38}$ RAMIRO AVILÉS, M. A.; "La utopía del Derecho", Anuario de Filosofia del Derecho, 19, 2002, pp. 435 y ss., https://www.boe.es/publicaciones/anuarios derecho/abrir pdf.php ?id= ANU-F-2002-10043100460.

39 Pensamos que este sería el caso. En la edición de 1599 el autor utiliza la palabra 'leges' tanto para hacer referencia a las escritas como a las que hubo en un inicio. MARIANAE, I.; De rege et regis institutione Libri III, Toleti, Apud Petrum Rodericum, 1599, p. 23. Curiosamente, según Mariana las leyes surgen para controlar la maldad de las personas, y esta es una característica también propia del pensamiento utópico (sobre ello RAMIRO AVILÉS, M. A.; "Estudio introductorio", pp. 22, 24). 
consecución. El pesimismo que afecta al discurso que venimos considerando parece relajarse, cuando Mariana da a entender que podría avanzarse en aspectos tales como el entendimiento de las leyes o, incluso de una manera mucho más pragmática, cuando, como veremos después, en su Discurso plantea algunas soluciones concretas para afrontar la prolijidad. En estos contextos el ideal inalcanzable, que parece desprenderse del análisis precedente, cede el paso a la propuesta de progreso $^{40}$.

La mixtura de percepciones expuesta podría considerarse el reflejo de dos tendencias que parecen estar presentes en Mariana, al menos según determinadas interpretaciones: de un lado su pesimismo y de otro la idea de que la persona puede superar adversidades ${ }^{41}$; las circunstancias son complicadas, pero también es posible mejorar. Por otra parte, el planteamiento podría considerarse en clave cronológica. Desde este punto de vista el desarrollo anterior muestra a un

40 Sobre estas cuestiones, en general, POCH, A.; "Estudio preliminar", en Moro, T.; Utopía, Madrid, Tecnos, 1987, pp. LXXVII-LXXVIII. Podría decirse que el discurso del autor cumple con las funciones crítica y compensatoria de la utopía, y también, siquiera en cierta medida, con la terapéutica, que remite a la posibilidad de que se lleven a cabo las recomendaciones. Sobre estas funciones RAMIRO AVILÉS, M. A.; "Estudio introductorio", pp. 20, 25.

${ }^{41}$ Esta circunstancia (no directamente referida al ámbito que ahora nos ocupa, pero sí expuesta a propósito de cuestiones que consideraremos después), se recoge en numerosas ocasiones en DUARTE SILVA, L.; $O$ direito de resistência e o tiranicidio no pensamento político de Juan de Mariana: contextualização, apresentação e a justificação do direito de resistência, Tesis Doctoral, Porto Alegre, 2017, p. 119, http://tede2.pucrs.br/tede2/bitstream/tede/7539/2/TES LUCAS D UARTE SILVA COMPLETO.pdf. escritor que aunque no se enmarca en la literatura utópica, sí que participa de ciertos detalles de aquella que, incluso, desde una perspectiva general, van más allá de lo dicho en el desarrollo precedente $^{42}$. Por otra parte, Mariana también aboga por ideas que se defenderían con especial fuerza siglos después. Sin embargo, como vamos a ver, la distancia cronológica que separa al jesuita de los postulados ilustrados, encuentra también reflejo en las propuestas desarrolladas en cada caso.

\section{Algunas consideraciones con la mirada en la}

\section{Ilustración}

El resumen de las características que el jesuita desea para la ley hace inevitable que centremos la mirada en la época de la Ilustración, pues en ella aquellas fueron especialmente reivindicadas:

42 En la literatura utópica la atención se centra en los estratos sociales más bajos, se plantea una sociedad comunista sustentada en el principio de igualdad, frente a la estructura burguesa de la Ilustración, y autores como Moro, aun considerando la libertad de conciencia, ven en la verdadera Iglesia la clave de la unidad y la paz (HORKHEIMER, M.; "La Utopía", Equipo Editorial (trad.), en Muniesa, B. (selec. y present.), Sociología de la Utopía, Barcelona, Hacer, 1992, pp. 117 y ss). Cabría señalar, no obstante, que el modelo comunal no es exclusivo en la utopía, que además comprende sistemas nuevos de propiedad privada (RAMIRO AVILÉS, M. A.; "Estudio introductorio", p. 21). En la obra de Mariana la Iglesia juega el mismo papel (aunque no se reconoce la libertad de conciencia), se formula claramente la distribución de la riqueza y se crítica su acumulación (DE MARIANA, J.; La dignidad real..., pp. 400-406). Incluso la defensa de preservar las riquezas de la Iglesia presente en Mariana, se acerca al parecer de Moro. Así hemos de entenderlo, si tenemos en cuenta el testimonio de Ribadeneyra, que informa de que el autor inglés defendió las riquezas de la Iglesia, necesarias para mantener la república y asistir a las personas pobres. DE RIBADENEYRA, P.; Historia ecclesiastica del scisma del Reyno de Inglaterra, Madrid, En casa de Pedro Madrigal, 1588, pp. 83, 84. 
establecimiento de leyes escritas, generales, con un lenguaje sencillo, accesible a todas las personas, claro, no ambiguo ni voluminoso, etc. ${ }^{43}$ Teniendo en mente todo ello, en un primer momento resulta tentador ver en el autor un antecedente de los planteamientos que se desarrollaron en siglos posteriores al suyo. Sin embargo, pensamos que esta afirmación, como poco, debería matizarse.

En principio, cabría señalar que los desarrollos difieren en cuanto a la perspectiva de análisis, pues en el pensamiento ilustrado el proceso legislativo recibe una atención que en Mariana es secundaria, y que trae causa de los análisis centrados en los poderes real y judicial ${ }^{44}$. La diferencia encuentra reflejo en los ámbitos cualitativo y cuantitativo (representativo de este último es el menor desarrollo en el caso de Mariana). De otro lado, el orden jurídico establecido por el Derecho común del que, como ya vimos, participa Mariana, no tiene acomodo en los planteamientos ilustrados. Para Bentham, por ejemplo, no es recomendable ajustarse a aquel, sino a una codificación que recoja el cuerpo del derecho, libre de discusiones históricas y citas romanas ${ }^{45}$. Estas apreciaciones reflejan una

43 PRIETO SANCHÍS, L.; Ley, principios, derechos, Madrid, Dykinson, 1998, p. 8; MARCILLA CÓRDOBA, G.; op. cit., pp. 93-95.

44 Sobre esta idea, expresada en términos generales, PRIETO SANCHÍS, L.; op. cit., pp. 6-7.

${ }^{45}$ BENTHAM, J.; Tratados de legislación civil y penal, Rodríguez Gil, M. (ed.), Madrid, Editora Nacional, 1981, p. 531. Con sus evolución histórica, pero un análisis detenido aporta ideas como la siguiente. Desde la perspectiva ilustrada el Derecho común es fuente de incertidumbre ${ }^{46}$, al menos en parte -pensamos-, por el papel que desempeñaba en él la interpretación, y que la Ilustración pretendía reducir a mínimos. Sin embargo, como sabemos, aunque Mariana denuncia los abusos en este ámbito, no renuncia a su práctica, ni la desestima en lo judicial.

Más concretamente, puede resultar interesante que centremos la atención en la promulgación de las leyes. Como ya vimos, según el jesuita aquella sucedió a un contexto anómico y por ello, en su discurso probablemente deba verse un signo diferencial con respecto a la costumbre ${ }^{47}$. No obstante, debe señalarse que esta sigue jugando un papel importante en el pensamiento del autor. Sin embargo, como veremos en este espacio, dicha fuente fue blanco de críticas en el periodo ilustrado $^{48}$. Desde esta perspectiva la codificación supuso una ruptura con respecto a aquella,

apreciaciones Bentham parece estar pensando en los códigos que ya no recogen ni consolidan el derecho antiguo, sino que se dedican a una rama del derecho. Sobre ello, en términos generales, GARCÍA-GALLO, A.; op. cit., pp. 225, 226.

${ }^{46}$ BENTHAM, J.; Tratados..., p. 529.

47 De nuevo, sobre la ley como "norma establecida", frente al derecho consuetudinario, GARCÍA-GALLO, A.; op. cit., p. 200.

${ }^{48}$ PRIETO SANCHÍS, L.; op. cit., p. 7. 
considerándose únicamente derecho aquel que se encontraba positivizado ${ }^{49}$.

En un primer acercamiento, el aspecto recientemente citado también parece marcar distancias con respecto a Mariana, más allá de lo dicho sobre la costumbre; pues aunque el autor considera el establecimiento de leyes escritas, también parece dar cuenta de otra fórmula cuando dice: "el rey que sólo promulga de palabra sus edictos y las leyes de sus antepasados" $"$. Pensamos, no obstante, que aquí el jesuita centra la atención en la -no ya promulgación sinopublicación mediante el pregón ${ }^{51}$; y que ello no impide admitir que en tal circunstancia pudiera haber tenido en mente también la impresión de textos $^{52}$. Este planteamiento no es lejano al ilustrado, pues también en él había lugar para la lectura pública, aunque ha de entenderse que no

49 SUÁREZ LLANOS, L.; "Razón, política y legislación (I). El liberalismo político: redentor y verdugo del derecho", en Martínez Roldán, L., Fernández Suárez, J. A., Suárez Llanos, L.; La ley desmedida. Estudios de Legislación, Seguridad y Jurisdicción, Madrid, Dykinson, 2007, pp. 67, 71, 72.

${ }^{50}$ DE MARIANA, J.; La dignidad real ..., p. 108.

${ }^{51} \mathrm{Al}$ menos en la primera parte del texto transcrito, quizá Mariana se esté refiriendo a las disposiciones del Consejo Real. Sin embargo, debe puntualizarse que las reales provisiones o cédulas se redactaban y se firmaban por el rey, quedando así promulgadas. Después, si eran de interés general, se publicaban con pregón. GARCÍA-GALLO, A.; op. cit., p. 221. La posibilidad que planteamos en el texto cobra fuerza, si tenemos en cuenta que en el punto que nos interesa Mariana utiliza la palabra 'figit', cuya traducción puede remitir a la publicación de leyes, y no 'promulgantur' como en otras ocasiones. MARIANAE, I.; De rege..., pp. 89, 102.

52 Así aconteció a partir del siglo XVI, como se señala en GARCÍA-GALLO, A.; op. cit., p. 221. eximía de la publicación de textos ${ }^{53}$. No obstante, debe señalarse que el alcance de la publicación impresa tenía diferente intensidad en cada caso $^{54}$ $\mathrm{y}$, lo más relevante, que desde una perspectiva general en el esquema ilustrado no hay cabida para el de Mariana, dado que en aquel la ley se considera fruto de la voluntad popular (no de la corona), al menos formalmente.

Puede resultar interesante que consideremos también el carácter general de las leyes, presente tanto en el discurso de Mariana como en el de la Ilustración. Sin embargo, la fundamentación -y, en consecuencia, también la puesta en prácticaen uno y otro caso es diferente. En el segundo el aspecto en cuestión fue un objetivo de la burguesía, que pretendía el fin de los estamentos $^{55}$, y en el caso del jesuita nos encontramos con que es un defensor de aquellos. De este modo, además del ius commune admite otro ius especial de carácter particular ${ }^{56}$, que parece enfrentarse al primero. Mariana probablemente habría explicado la cuestión del siguiente modo. Para él, las preferencias en este ámbito tienen su fundamento, entre otras cosas y

\footnotetext{
${ }^{53}$ Puede verse, por ejemplo, BENTHAM, J.; Tratados ..., pp. 575578.

${ }^{54}$ En lo que toca a las pragmáticas, el texto impreso se mandaba a las autoridades (GARCÍA-GALLO, A.; op. cit., p. 221), y en la Ilustración se pretendía dar las facilidades que fueran necesarias para que la audiencia pudiera consultar la ley (BENTHAM, J.; Tratados..., p. 575).

55 MARCILLA CÓRDOBA, G.; op. cit., pp. 89, 94; SUÁREZ LLANOS, L.; op. cit., p. 44.

${ }^{56}$ Sobre ambos tipos GARCÍA-GALLO, A.; op. cit., p. 243.
} 
aunque parezca paradójico, en la preservación de ausencia de diferencias entre las clases del Estado $^{57}$. Así, en el caso del estamento eclesiástico la Iglesia preserva la religión del reino que, a su vez, posibilita el bien común ${ }^{58}$. Más concretamente, las riquezas en este contexto se justifican porque revierten en las personas más necesitadas que, por cierto, son las propietarias ${ }^{59}$. Son precisamente estas obligaciones para con la comunidad, las que se aducían en la época para justificar que los privilegios eran acordes con la razón de la ley. Sin embargo, tal planteamiento se enfrenta a la apuesta por la igualdad $\operatorname{posterior~}^{60} \mathrm{y}$, por ende, a la burguesía ilustrada. Debemos entender, por tanto, que la formulación del carácter general de las leyes que Mariana tuvo en mente, estuvo marcada por especificidades derivadas de la situación en la que vivió, que si bien despedía al medievo reciente y anunciaba la

${ }^{57}$ DE MARIANA, J.; La dignidad real ..., p. 284.

58 DE MARIANA, J.; La dignidad real..., p. 281. Este punto presenta otro aspecto más que separa al religioso de la Ilustración. Donde aquel ve una garantía para el bien común, Bentham advierte razones de poder, reputación o riqueza (BENTHAM, J.; Tratados..., p. 530). En aquel la religión es imprescindible para unir al pueblo, y en este divide más que reúne. Sobre este y otros planteamientos de Bentham relativos a la religión CLÉRO, J. P.; "Bentham, crítico de la religión", Torres Rosell, N. y Escamilla Castillo, M. (trad.), Anales de la Cátedra Francisco Suárez, 48, 2014, p. 186 , http://revistaseug.ugr.es/index.php/acfs/article/view/2784/2901.

${ }^{59}$ DE MARIANA, J.; La dignidad real ..., p. 404.

${ }^{60}$ Sobre ello GARCÍA-GALLO, A.; op. cit., p. 243, que se refiere a Suárez. Hemos localizado desarrollos en esta línea en SUÁREZ, F.; Tratado de las leyes y de Dios legislador, vol. III, Eguillor Muniozguren, J. R. (trad.), Madrid, Instituto de Estudios Políticos, 1968 , pp.459 y ss. modernidad, todavía quedaba lejana de la Ilustración y arrastraba circunstancias del pasado.

No obstante, y aun habiendo constatado las diferencias anteriores, cabría señalar que tanto en el caso del jesuita como en el de la Ilustración, encontramos puntos de conexión en recomendaciones tales como las de claridad, brevedad y sencillez de las leyes ${ }^{61}$. Sin embargo, un análisis detenido nos descubre distancias también en esta ocasión. En el planteamiento que Mariana ofrece sobre estas cuestiones, así como en el de la Ilustración, subyace una tensión entre características tales como la claridad y la brevedad de las normas (en buen número de casos la promoción de una irá en detrimento de la otra).

Es cierto que en la última época no parece que se resolviera dicho enfrentamiento del mismo modo ${ }^{62}$, pero la comparación pormenorizada entre las soluciones propuestas por el jesuita, y aquellas recogidas en determinadas obras, descubren diferencias considerables.

Con vistas a reducir el número de leyes o su contenido, en su Discurso Mariana propone evitar lo que él llama 'menudencias', y sobre ello ofrece algunos ejemplos concretos. De este modo,

${ }^{61}$ Puede verse, por ejemplo, BENTHAM, J.; Nomografía o el arte de redactar leyes, Pabón, C. (trad.), Madrid, Centro de Estudios Políticos y Constitucionales, 2004, pp. 27 y ss.; BENTHAM, J.; Tratados..., pp. 528 y ss.; ANÓNIMO; Descripción de la Sinapia, península en la tierra austral, Madrid, Dykinson, 2013, p. 78.

62 Sobre ello FERRERES COMELLA, V.; El principio de taxatividad en materia penal y el valor normativo de la jurisprudencia (Una perspectiva constitucional), Madrid, Civitas, 2002, p. 38. 
considera que en vez de ir enumerando las reglas que han de observarse en la vida cotidiana de la Compañía (no mortificarse en público, salir de la celda bien vestido, bendecir la comida, etc.), se podría ordenar simplemente que se guarden "los usos de las Casas de la Compañía"63. Por otro lado, se refiere a una orden de la Constitución jesuítica, que establecía que antes de que una obra se imprimiese debía ser vista por tres religiosos. Mariana considera innecesario que a partir de este texto se hiciesen más de doce ordenanzas, como así aconteció; pues simplemente habría sido suficiente con constatar "que los Provinciales sean tales, y los que vén los libros sean personas enteras" $"$.

Las propuestas anteriores contrastan con las que, por ejemplo, propone Bentham para lograr brevedad. Sus recomendaciones pasan por la división del texto en varias partes. Además, considera numerosos defectos que han de evitarse, como las tautologías, repetición de definiciones, etc. De otro lado, advierte del cuidado que ha de tenerse para no omitir nada de la ley que afecte a la audiencia ${ }^{65}$. Como vemos, las recomendaciones en este caso transcurren por cauces diferentes. La distancia entre propuestas se confirma, si se acepta la afirmación general que

\footnotetext{
${ }^{63}$ DE MARIANA, J.; Discurso..., p. 221.

${ }^{64}$ Ibídem, pp. 221, 222.

65 BENTHAM, J.; Nomografia..., pp. 53; BENTHAM, J.; Tratados..., p. 533.
}

ve entre las características de la codificación ilustrada la de elaborar leyes exhaustivas, capaces de alcanzar a todos los ámbitos de la realidad ${ }^{66}$. Una manifestación de ello se aprecia en el siguiente texto de la obra Sinapia: "apartados por las leyes de lo / superfluo, con tanta menudencia, que hasta el menor instrumento y la menor alhaja, está determinado por las leyes del tamaño, la materia y la forma que han de tener y hasta la más leve cortesía cómo se ha de practicar" ${ }^{\circ 7}$.

Hemos de señalar también que la línea de análisis expuesta adquiere aún más fundamento, si recordamos que, al menos en algún caso, el jesuita parece considerar factible el recurso a los usos de un contexto determinado. Sin embargo, como ya señalamos el pensamiento ilustrado recoge entre sus críticas más contundentes las dirigidas a la costumbre, probablemente, entre otras razones, por la incertidumbre que ocasionaba y su disposición a la interpretación.

${ }^{66}$ SUÁREZ LLANOS, L.; op. cit., p. 72.

${ }^{67}$ ANÓNIMO; op. cit., p. 76. El enfrentamiento entre este texto y el recogido en el Discurso es evidente. Llama la atención que en ambos se utiliza la palabra 'menudencias'. Estos detalles, y otros presentes en Sinapia, claramente opuestos a las ideas de Mariana (por ejemplo, que los eclesiásticos no tuvieran bienes particulares y que se emplearan en su ministerio, p. 92 de la obra), alimentan la hipótesis de que fuera Campomanes el autor de la obra (sobre esta posibilidad RAMIRO AVILÉS, M. A.; "Estudio introductorio", p. 27). A propósito de ello, han de tenerse en cuenta los ataques de aquel al jesuita, con ocasión de la expulsión de la Orden, así como la publicación por entonces del Discurso del autor, también con fines críticos. Sobre ello CENTENERA SÁNCHEZ-SECO, F.; "De Toledo a Londres: el último viaje de Juan de Mariana", Cabeza encantada. Humanism e-review, 2011, pp. 16, 17, http://www.proyectos.cchs.csic.es/humanismoyhumanistas/sites/pr oyectos.cchs.csic.es.humanismoyhumanistas/files/CENTENERA \%20DE $\% 20$ TOLEDO $\% 20 \mathrm{~A} \% 20 \mathrm{LONDRES}(2) \quad 0 . \mathrm{pdf}$. 


\section{Algunas consideraciones desde nuestro} tiempo

Vistos desde nuestra época, los planteamientos del jesuita recuerdan a numerosos desarrollos que nos quedan más cercanos. Desde una perspectiva general, resulta interesante constatar que en nuestro tiempo, los problemas en torno a la ley se diagnostican a propósito de la creciente normativa internacional y estatal, o de aspectos de tipo lingüístico o lógico, que contribuyen a la oscuridad normativa ${ }^{68}$. Curiosamente, las circunstancias estructurales parecen repetirse, si bien su análisis pormenorizado daría lugar a importantes diferencias en las que aquí no podemos detenernos.

Más concretamente, podemos centrar la atención en la promulgación legislativa que, como vimos, para Mariana supone el establecimiento de la ley. Tal planteamiento parece remitir a la idea de esencialidad de la promulgación para poder decir que una ley existe; presente también en nuestro tiempo $^{69}$. El análisis sobre el carácter general de las leyes también puede resultar sugerente desde

68 ZAPATERO, V.; El Arte de Legislar, Pamplona, Aranzadi, 2009 , pp. 28 y ss. Sobre la primera cuestión también HIERRO, L. L.; "El imperio de la ley y la crisis de la ley", Doxa, 19, 1996, pp. 296-298, https://rua.ua.es/dspace/bitstream/10045/10482/1/doxa19 15.pdf; PÉREZ MARTÍN, A.; op. cit., p. 92.

${ }^{69}$ Puede verse, por ejemplo, PÉREZ LUÑO, A.-E.; La seguridad jurídica, Barcelona, Ariel, 2. ${ }^{\mathrm{a}}$ edición revisada y puesta al día, 1994, p. 32. la perspectiva que nos ocupa. Quizá sea interesante recordar en este punto la obra de Fuller, que presenta a un gobernante ficticio tratando de afrontar una situación en la que, como en la exposición de Mariana, encontramos juicios negligentes y corrompidos ${ }^{70}$. También en este caso, como en el del jesuita, se constatan los problemas derivados de la inexistencia del carácter general en las leyes $\mathrm{y}$, con ello, su oportunidad $^{71}$. A propósito de la misma cuestión, podríamos preguntarnos también si Mariana considera la generalidad en el doble sentido que, por ejemplo, se aprecia en Hart (indicación de "un tipo general de conducta" y aplicación a "una clase general de personas" ${ }^{\text {"72}}$ ); es decir, si en su discurso puede diferenciarse entre lo que hoy conocemos como carácter general y abstracto $^{73}$. $\mathrm{Si}$ repasamos textos como el que sigue, parece que tendríamos que responder que el planteamiento entra dentro de los anhelos del autor que, además, apunta a niveles altos en ambas dimensiones: "[...] leyes que tuviesen siempre el mismo sentido para todos"74 (cursiva nuestra).

\footnotetext{
70 FULLER, L. L.; La moral del derecho, Navarro, F. (trad.), México, Trillas, 1967, pp. 43 y ss.

${ }^{71}$ Ibídem, p. 44.

72 HART, H. L. A.; El Concepto de Derecho, Carrió, G. R. (trad.), Buenos Aires, Abeledo-Perrot, segunda edición (reimpresión), 2004, p. 27.

73 BOBBIO, N.; Teoría general del derecho, Guerrero, R., J. (trad.), Bogotá, Temis, quinta reimpresión de la segunda edición, 2005, p. 130.

${ }^{74}$ DE MARIANA, J.; La dignidad real..., p. 27.
} 
No obstante, debe tenerse en cuenta que la transcripción anterior se enmarca en el relato de los primeros tiempos, y que por ello debería entenderse que el jesuita considera inalcanzable tal circunstancia en su época. A propósito de ello, debemos recordar su preferencia por los estamentos, aspecto que matiza de forma importante la cuestión que nos ocupa. Además, por lo que respecta a nuestra época hemos de considerar que la característica también se ha reformulado, no únicamente por las razones ilustradas, sino también como superación de aquellas por el Estado social. La dimensión distributiva de este parece diluir la generalidad de las leyes ${ }^{75}$, o al menos la reformula en determinados casos frente a la idea ilustrada de leyes para todas las personas. Como ya vimos en el caso de Hart, el carácter general remite a una clase de personas $^{76}$. No obstante, debería apuntarse que la apuesta por la distribución de la riqueza de Mariana que, por ejemplo, incluye el establecimiento de impuestos a la riqueza ${ }^{77}$, participa de tal circunstancia; siquiera en algún grado. A nuestro modo de ver, la propuesta del autor que da lugar a la singularidad en determinadas leyes frente al derecho común, encuentra acomodo en lo que Suárez denomina

75 GALIANA SAURA, Á.; La legislación en el Estado de Derecho, Madrid, Dykinson, 2003, pp. 61 y ss.

${ }^{76}$ HART, H. L. A.; op. cit., p. 27; BOBBIO, N.; op. cit., p. 130; LAPORTA, F. J.; El imperio de la ley. Una visión actual, Madrid, Trotta, 2007, pp. 88, 89.

${ }^{77}$ DE MARIANA, J.; La dignidad real ..., p. 402. "leyes odiosas", entre las que encontramos las tributarias, que suponen una aportación al bien común ${ }^{78}$. La contribución a este se presenta de nuevo como fundamento de la reducción del carácter general, y habría que entender además que las desigualdades de la época son las que imposibilitan que se puedan alcanzar cotas más altas en aquel.

Otro tema que podemos considerar es el de la claridad de las leyes, que también tiene en cuenta Fuller. En este punto el profesor de Harvard se separa del pensamiento ilustrado, al aceptar la vaguedad en el texto normativo, aunque eso sí, dependiendo del caso que se trate. En tales supuestos ha de tenerse la seguridad de que la audiencia de la ley conoce a qué se refiere esta con dichas fórmulas ${ }^{79}$. En un primer acercamiento, este planteamiento parece estar en consonancia con la apuesta de Mariana por fórmulas como "usos de la Compañía" o "persona entera". Ciertamente, podría considerarse que recursos de este tipo van en perjuicio de la claridad. No obstante, también es cierto que en determinados casos la vaguedad puede dar lugar a pocos o ningún caso marginal ${ }^{80}$. Así, no tendría por qué existir problema si es posible concretar las palabras o expresiones de forma razonable, a

\footnotetext{
${ }^{78}$ SUÁREZ, F.; Tratado de las leyes..., vol. III, pp. 460 y ss.

${ }^{79}$ FULLER, L. L.; op. cit., p. 76.

80 ENDICOTT, T.; Palabras y Reglas. Ensayos en filosofía del derecho, Navarro, P. (trad.), México, Distribuciones Fontamara, 2004, pp. 81, 82 .
} 
partir de criterios de tipo lógico, técnico o de experiencia ${ }^{81}$.

En su discurso Mariana parece ser muy optimista con respecto a la cuestión que tratamos, pero desde nuestro tiempo sus propuestas suscitan numerosos interrogantes. Podrá decirse que el análisis en esta línea es sesgado, al menos en parte, pues no conocemos toda la información que tuvo en mente el jesuita. Sin embargo, aun así pensamos que merece la pena plantear las siguientes reflexiones. Cuando Mariana habla de "personas enteras", cabría preguntarse, por ejemplo, si la expresión alcanzaba a quienes criticaban a la Compañía. Quizá él respondería afirmativamente (su Discurso se desarrolla en esa línea), pero este probablemente no sería el parecer de otros religiosos de la Orden. Ciertamente, la terminología con textura abierta puede tener lugar si se tiene en cuenta lo ya dicho, pero parece que Mariana va más allá de lo recomendable. Quizá una muestra de ello sean los matices emocionales $^{82}$ que suscita la expresión que nos ocupa. No obstante, la cuestión incluso podría plantearse con respecto a palabras que, al menos prima facie, tienen una zona de penumbra mucho más reducida. Así, por ejemplo, a propósito de la cuestión de la revisión de las obras por tres

${ }^{81}$ Sobre estas cuestiones ARCOS RAMÍREZ, F.; La Seguridad Jurídica: Una Teoría Formal, Madrid, Dykinson, 2000, p. 263.

82 No recomendable, por tanto. Sobre ello, por ejemplo, XANTHAKI, H.; Thorton's Legislative Drafting, Great Britain, Bloomsbury Professional, fifth edition, 2013, p. 77. religiosos, el autor señala que sería suficiente con comprobar que los provinciales fueran tales. No obstante, ello suscita preguntas como la siguiente: ¿quién tendría que firmar la facultad de impresión de la obra, un provincial? Por ejemplo, en la Historia ecclesiastica de Ribadeneyra ${ }^{83}$ acontece de tal modo, pero no parece que fuera así en el $D e$ rege, donde leemos la firma de un visitante en la provincia toledana ${ }^{84}$.

La cuestión se complica aún más, si en vez de tener en mente una comunidad reducida, como puede ser una Orden, centramos la atención en la comunidad política. En este contexto nos encontramos con que en más ocasiones, las leyes no tendrán una única audiencia, sino dos o más ${ }^{85}$. Tal circunstancia cuestiona además la propuesta del jesuita de dejar las leyes que pudieran entender todas las personas. La complejidad en este punto se pone de manifiesto, si tenemos en cuenta que el lenguaje jurídico se compone en parte de lenguaje técnico (también en la época de Mariana), y que por ello su sencillez quedará limitada ${ }^{86}$.

Además de lo anterior, los desarrollos del autor también parecen encontrar reflejo en otros planteamientos iusfilosóficos de nuestro tiempo.

\footnotetext{
${ }^{83}$ DE RIBADENEYRA, P.; op. cit., sin paginar.

${ }^{84}$ MARIANAE, I.; De rege..., sin paginar.

${ }^{85}$ ZAPATERO, V.; El Arte de Legislar, pp. 266, 267.

${ }^{86}$ LAPORTA, F. J.; op. cit., p. 93.
} 
En su Discurso constata que hacer muchas leyes y que estas sean precisas es como si a una persona, después de nacer, se le hicieran vestidos para toda su vida. Ciertamente, en esta labor sería muy complicado acertar, pues el cuerpo puede ser más o menos grande de lo que en un principio se pudiera considerar e, igualmente, sería erróneo pensar que aquella persona usase dichos vestidos, simplemente porque se los confeccionaron de tal manera cuando nació ${ }^{87}$. De otro lado, en relación a las ordenanzas de la Constitución jesuítica, como sabemos el autor dice que no son necesarias, siendo suficiente con asegurarse de que, por ejemplo, quienes examinen las obras sean personas 'enteras'. De este modo, "se acude à todo $\sin$ tantas novedades y alteraciones" ${ }^{\prime 88}$.

Con los planteamientos expuestos Mariana se muestra partidario de evitar lo que hoy conocemos como hiper-precisión ${ }^{89}$ o detallismo ${ }^{90}$, y también diagnostica los costes actuales de la de la precisión: la voluminosidad $\mathrm{y}$, por ende, un difícil manejo de las leyes ${ }^{91}$. Más concretamente, resulta interesante constatar que en su discurso, de algún modo parecen estar presentes los fracasos que considera Endicott, cuando se refiere al supuesto de una regulación muy específica: por

${ }^{87}$ DE MARIANA, J.; Discurso..., p. 217.

${ }^{88}$ Ibídem, p. 222.

${ }^{89}$ ZAPATERO, V.; El Arte de Legislar, p. 265.

90 ASTARLOA, I.; (dir. y coord.), Memento práctico. Técnica Normativa, Madrid, Francis Lefebvre, 2015, p. 119.

${ }^{91}$ FERRERES COMELLA, V.; op. cit., pp.37-39. una parte, será inútil como guía de conducta para las personas y para la aplicación normativa; por otra parte, resulta imposible anticipar con tanta precisión, y probablemente alguien podría inventar una conducta que pudiera caer fuera de la regulación establecida ${ }^{92}$. En palabras del jesuita, el detalle desmedido va parejo a la especulación, de la que resultan las circunstancias expuestas ${ }^{93}$.

No obstante, cabría apuntar que la vaguedad en la regulación, derivada de lo recientemente dicho, aunque no supone necesariamente un problema para la claridad $^{94}$, como ya señalamos, puede suscitar dudas que deberán resolverse en el futuro. Ante tal circunstancia hoy se proponen soluciones como la delegación en un órgano administrativo que concrete, o bien la vía judicial ${ }^{95}$. Como sabemos, Mariana contempla la interpretación en los juicios en el De rege. Por otra parte, en el Discurso considera que en caso de abuso, este debe remediarse o castigarse, y no publicar una ley nueva ${ }^{96}$. Podemos entender que la interpretación tiene cabida en ambos casos, pero al menos de forma suficientemente explícita, el autor no muestra los problemas que pueden surgir en aquella a propósito de la determinación del

\footnotetext{
92 ENDICOTT, T.; op. cit., pp. 80, 81. Sobre la última cuestión puede consultarse también FERRERES COMELLA, V.; op. cit., p. 35 .

${ }^{93}$ DE MARIANA, J.; Discurso..., p. 217.

${ }^{94}$ ENDICOTT, T.; op. cit., p. 81.

${ }^{95}$ HART, H. L. A.; op. cit., pp. 163-165.

${ }^{96}$ DE MARIANA, J.; Discurso..., p. 222.
} 
significado de las palabras o expresiones con textura abierta. Quizá, de nuevo, debamos ver aquí una muestra de su confianza en la audiencia de la ley, a la hora de determinar el significado ${ }^{97}$, resultante del papel relevante que atribuye a los usos. No obstante, tal planteamiento contrasta con otros coetáneos, que probablemente debieran considerarse más realistas, como el de Suárez, para quien las fórmulas breves y generales traerán consigo dudas a la hora de aplicar la ley ${ }^{98}$.

Además de todo lo dicho, pensamos que es interesante señalar que en el discurso de Marina que critica la prolijidad legislativa y su precisión prolongada, parece estar presente la idea de que todo aquello va también en detrimento ${ }^{99}$ de otra característica normativa que tenemos muy en cuenta en nuestro tiempo ${ }^{100}$ y que, como ya vimos, podemos localizar además en el pensamiento del autor. Nos referimos a la estabilidad de las normas. El autor parece estar

\footnotetext{
${ }^{97}$ Podría considerarse que ello contradice la realidad de la época - de la que fue consciente Mariana- en la que, como sabemos, se desarrollaron interpretaciones enfrentadas sobre un mismo texto legislativo. Sin embargo, la contradicción únicamente es aparente, si se acepta el argumento de que para Mariana, en el caso citado la disparidad trae causa, bien de cuestiones lingüísticas como la ambigüedad, bien del abuso en la interpretación, y no de la capacidad de las personas para determinar el significado de la ley.

98 Tratamos el tema en CENTENERA SÁNCHEZ-SECO, F., “El lenguaje de la ley...", p. 138.

99 Hemos tratado la cuestión desde el punto de vista actual en CENTENERA SÁNCHEZ-SECO, F.; "Los paradigmas de redacción normativa como medio para alcanzar la seguridad: ¿una apuesta segura?", Ius Humani. Revista de Derecho, 3, 2012/2013, p. 203, http://oaji.net/articles/2015/1706-1424886391.pdf.

100 Véase, por ejemplo, FULLER, L. L.; op. cit., pp. 92-94; PÉREZ LUÑO, A.-E.; op. cit., p. 34.
}

reparando en ello cuando, por ejemplo, señala que si se utilizan expresiones con textura más abierta no serán necesarias tantas novedades.

\section{La contribución a la limitación del poder}

A nuestro modo de ver, las características que considera Mariana vienen motivadas por la intención de ajustar los comportamientos a lo establecido en las leyes. En parte, podría decirse que la pretensión se dirige a las personas en general. Las apreciaciones del autor relativas a los perjuicios que causan la prolijidad y la oscuridad en el cumplimiento y la comprensión, entendemos que se desarrollan en la línea descrita. No obstante, consideramos que su discurso incide de una forma especial en quienes tienen el poder, que también deben ajustar sus acciones al marco legal establecido. Recordemos, por ejemplo, que la promulgación de leyes generales se lleva a cabo para evitar arbitrariedades, o que se solicita evitar ambigüedades para que estas no se aprovechen con el fin de eludir las leyes en el ámbito judicial.

Si la interpretación anterior es correcta, pensamos que su última parte podría enmarcarse dentro de un contexto temático más amplio, desarrollado en los capítulos del De rege que analizan las cuestiones de si el poder real es mayor que el de la comunidad, y si quien tiene el poder debe guardar las leyes. En sus páginas podemos leer 
que la potestad regia legítima se establece por el consentimiento de la ciudadanía y se limita por las leyes ${ }^{101}$; siendo la actuación por propio interés genuina de la tiranía ${ }^{102}$. De este modo, quien gobierna debe obedecer las leyes y no alterarlas sin el consentimiento de la comunidad. Concretamente, en este punto el autor piensa en leyes sobre la sucesión real, la religión, en la imposición de tributos $\mathrm{y}$ en todos aquellos aspectos que la costumbre reserva al acuerdo común del pueblo ${ }^{103}$. Este planteamiento está también presente en el Discurso, donde podemos leer que la monarquía debe ir atada a las leyes ${ }^{104}$; y en los desarrollos del Tratado ${ }^{105}$, que sitúan al poder real por debajo del derecho. La postura resulta interesante, pues con ella el autor establece un límite al poder que no considera absoluto; enlazando así con la filosofía de la Ilustración, crítica con la legislación voluntarista de aquel ${ }^{106}$.

Si analizamos el planteamiento anterior desde nuestro tiempo, en un primer momento podría

\footnotetext{
${ }^{101}$ DE MARIANA, J.; La dignidad real ..., pp. 93, 107.

102 Ibídem, pp. 33, 69, 79, 80.

${ }^{103}$ Ibídem, pp. 98, 109.

${ }^{104}$ DE MARIANA, J.; Discurso..., p. 152.

${ }^{105}$ DE MARIANA, J.; Tratado..., pp. 31 y ss.

106 SUÁREZ LLANOS, L.; op. cit., pp. 26 y 27. La opción de Mariana adquiere más valor si examinamos circunstancias concretas de la época, que constatan las pugnas entre el poder real y las Cortes. Así, por ejemplo, la suscitada a consecuencia de la posible derogación de las leyes de las Cortes por pragmáticas reales; algo reconocido en Castilla, pero no en los restantes territorios del reino. Mariana, con su propuesta, se muestra partidario de la opción presente en los últimos contextos citados (sobre estas cuestiones, consúltese también la referencia citada al comienzo de esta nota al pie).
}

decirse que con sus recomendaciones el jesuita trata de presentar contribuciones a lo que hoy conocemos como imperio de la ley. El planteamiento puede reforzarse si asumimos la interpretación de que Mariana constituye un antecedente del constitucionalismo, cuya relevancia se aprecia en nuestra época si trasladamos los límites que establece con respecto al poder, a aquellos ámbitos en los que hoy se ejerce (presidencia, parlamentos, etc.). Se trataría, en definitiva, de un desarrollo en la línea de lo que conocemos como interpretación débil del imperio de la ley ${ }^{107}$. En base a ella entendemos, por ejemplo, que la generalidad es necesaria para

107 El desarrollo de Mariana invita también a plantear una comparación con la versión fuerte del imperio de la ley, donde esta es "expresión mediata o inmediata de la voluntad general" (HIERRO, L. L.; op. cit., p. 289. Desarrollada en DÍAZ, E.; Estado de Derecho y sociedad democrática, Madrid, Taurus, $4^{\mathrm{a}}$ edición, 2010, pp. 46, 47). Sin embargo, también en este caso hay diferencias. Cuando Mariana cita al pueblo no siempre queda claro a qué se refiere. Pensamos, no obstante, que al menos en numerosas ocasiones, piensa en Cortes compuestas por nobleza, clero y representantes de las ciudades (DE MARIANA, J.; La dignidad real ..., pp. 101, 102, 118). Ciertamente, no se trata de un órgano que represente al pueblo, elegido de forma libre. Aquel no constituye el límite del poder, sino los estamentos (sobre tal circunstancia DÍAZ, E.; op. cit., pp. 40, 46). Podría decirse que el jesuita considera a los procuradores de las ciudades, pero al menos explícitamente, no dice que su elección resulte de la voluntad popular, sino que debe ser juiciosa y llevada a cabo por el brazo correspondiente (DE MARIANA, J.; La dignidad real..., p. 101). A lo más, pensamos que este desarrollo podría estar remitiendo a una participación parcial del vecindario. Sería posible argumentar en este sentido, si se admite que el autor pudiera estar pensando en un sistema de elección llevado a cabo por quienes componían los concejos: funcionariado local, representantes del consejo y capítulo, y vecindario (sobre estos datos relativos a la elección de procuradores puede consultarse PALACIOS MARTÍN, B.; "La representación municipal en Cortes. Estudio de la figura del Procurador de Zaragoza a mediados del siglo XV', España Medieval, 7, 1985, pp. 1243-1250, http://revistas.ucm.es/index.php/ELEM/article/viewFile/ELEM858 $\underline{5221241 \mathrm{~A} / 24614) \text {. }}$ 
impedir la arbitrariedad $^{108}$, o la claridad para limitar el poder y conformar los criterios de su actuación ${ }^{109}$; suponiendo $\mathrm{su}$ inexistencia incertidumbre en la aplicación de la norma ${ }^{110}$. Decimos, por ello, que los requisitos del imperio de la ley hacen posible la obediencia de las normas $^{111}$. Sin embargo, estos puntos de encuentro no deberían obstar para dejar también constancia de distancias importantes.

Por una parte, entendemos que la función que desempeñan las características que considera Mariana es limitada, porque el planteamiento que las enmarca no alcanza a todas las acciones del poder. En principio, cabría señalar que el autor aprueba determinados casos que considera arbitrarios. Así, se refiere a varios reyes que cambiaron lo establecido en el orden de sucesión a la corona. El jesuita sienta como regla general no dar lugar al arbitrio en este ámbito, pues la reforma de las leyes no compete a la corona, sino a la comunidad. No obstante, admite los ejemplos bíblicos de David y Jacob, que quitaron el poder a su primogénito. Detrás de ello debemos ver razones de justicia, consistentes en evitar agitaciones o peligros para el reino ${ }^{112}$. El autor

\footnotetext{
${ }^{108}$ HIERRO, L. L.; op. cit., pp. 288, 289.

${ }^{109}$ LAPORTA, F. J.; op. cit., pp. 163, 164.

110 Ibídem, pp. 86-93.

111 ANSUÁTEGUI ROIG, F. J.; Razón y voluntad en el Estado de Derecho. Un enfoque filosófico-jurídico, Madrid, Dykinson, 2013, p. 150.

112 DE MARIANA, J.; La dignidad real..., pp. 49, 50.
}

corrobora lo dicho con ejemplos cercanos a su época, si bien apunta que los cambios han de hacerse según lo establecido por consentimiento común y siguiendo la voluntad del pueblo ${ }^{113}$.

Por otra parte, para Mariana el sometimiento de la corona a otras leyes queda considerablemente relajado. Según él, quien tiene el poder ha de obedecer las leyes sancionadas por la república, pero el grado de exigencia es menor en el caso de las leyes que se ha dado para sí quien gobierna (en tal caso no se puede obligar a obedecer). La laxitud está presente también en lo que respecta a otras leyes que, no obstante, debe obedecer la ciudadanía, como las relativas a los gastos, represión del lujo, formas de vestir o prohibición de $\operatorname{armas}^{114}$. Además, el jesuita es condescendiente con la concesión de un "cierto arbitrio", aunque respaldado por la costumbre de los pueblos, en cuestiones tales como hacer la guerra, administrar justicia o establecer magistraturas y judicaturas ${ }^{115}$.

\footnotetext{
113 DE MARIANA, J.; La dignidad real..., pp. 58, 59. Sobre ello también la p. 108. El planteamiento dista mucho de las circunstancias de nuestro tiempo, pero también es cierto que la tensión entre el sometimiento a la ley y la justicia encuentra reflejo en aportaciones actuales. En este sentido, se considera una primera perspectiva, de carácter formal, desde la que se entiende que la arbitrariedad siempre es injusta; y una segunda, referida al contenido de los sistemas, desde la que se señala que la arbitrariedad puede ser justa cuando la respuesta que establezca la regla o su ausencia den como resultado una injusticia. ANSUÁTEGUI ROIG, F. J.; op. cit., pp. 158-160. Sobre la cuestión también LAPORTA, F. J.; op. cit., p. 218.

${ }^{114}$ DE MARIANA, J.; La dignidad real..., pp. 112, 113.

115 Ibídem, pp. 97, 98.
} 
Finalmente, habría que añadir también que un análisis general de las propuestas del autor, demuestra que en ellas el recurso a las leyes para limitar el poder tiene una intensidad modesta. Es decir, Mariana no tiene confianza plena en la ley como instrumento para limitar al poder. En su planteamiento, además de la vía jurídica se desarrollan otras en las que el autor parece depositar una parte considerable de sus esperanzas. Nos referimos a la religión y a la prudencia que proporciona el consejo de personas destacadas ${ }^{116}$. Lo primero probablemente traiga causa del papel que el autor atribuye a la providencia en la historia, como brazo que castiga las extralimitaciones del poder ${ }^{117}$. La razón de lo segundo quizá deba buscarse en el valor que el autor otorga al consejo, sin duda muy a propósito, habida cuenta de la inexistencia de separación de poderes en la época.

\section{La contribución a la justicia}

116 Sobre ello DUARTE SILVA, L.; op. cit., p. 117, PECESBARBA, G., SEGURA ORTEGA, M.; "La filosofía de los límites del poder", en Peces-Barba Martínez, G. y Fernández García, E. (Dir.), Historia de los derechos fundamentales, tomo I, Madrid, Dykinson, 1998, p. 440; y BRAUN, H. E.; Juan de Mariana and Early Modern Spanish Political Thought, Hampshire, Ashgate, 2007, pp. 77 y ss. (este autor advierte en Mariana un interés principal en la prudencia, en detrimento de las leyes, que apenas tienen relevancia).

117 Consideramos la cuestión en CENTENERA SÁNCHEZSECO, F.; "La cuestión del tiranicidio en Mariana y los reyes franceses del momento", Congreso Internacional la actualidad del padre Juan de Mariana (ponencia en prensa).
Teniendo en cuenta el desarrollo expuesto hasta el momento, cabría preguntarse acerca de la relación que pudiera establecerse entre las características de la ley consideradas y la idea de justicia en Mariana. Como sabemos, el autor no establece un discurso individual para el tema que nos ocupa, pero sus desarrollos sobre la justicia ofrecen algunos detalles para plantear la respuesta que nos proponemos abordar en este punto.

A nuestro modo de ver, en el pensamiento del jesuita las características que venimos estudiando podrían considerarse instrumentos necesarios (aunque insuficientes, por lo ya dicho en el apartado precedente) para hacer posible lo que el autor denomina justicia en términos generales. Esta remite a la idea de equidad, que es el lazo que une "por igual los derechos de las clases alta, ínfima y media" y que hace las veces de estructura que ordena la sociedad, sin la cual esta desaparecería $^{118}$. De este modo, podríamos considerar que aspectos formales como los que nos han ocupado, contribuyen de diferentes maneras a que sea posible la justicia y, a la vez, a evitar la arbitrariedad. Mariana no atribuye a aquellos un carácter moral per se, pero reconoce la contribución a la justicia de algunos de ellos. Así, por ejemplo, en lo que respecta al carácter general de la ley escribe lo siguiente: "Es sabido además que no hay nada que perturbe tanto la

${ }^{118}$ DE MARIANA, J.; La dignidad real..., p. 385. 
justicia como la ira, el odio [...] y ésta fue la principal causa de que se establecieran las leyes, por considerar que éstas tienen un carácter general y no se doblan a la fuerza de las pasiones" $" 119$.

El planteamiento también está presente en nuestro tiempo, pero resulta interesante constatar que en este caso se suele hacer referencia a la igualdad y la predecibilidad, tanto en relación a las conductas de otras personas, como a las de los poderes públicos ${ }^{120}$. Sin embargo, como ya vimos para Mariana la consecución de la igualdad, posible gracias al carácter general, tiene un esquema diferente al que encontramos en los siglos posteriores, y además no se refiere a la cuestión de la predecibilidad; quizá, pensamos, porque tiene principalmente en mente el bien de la comunidad, y no tanto a la persona considerada individualmente. Las referencias del autor al orden y subsistencia del sistema ${ }^{121}$ aportan fuerza a esta reflexión. En todo caso, si se acepta el planteamiento que venimos exponiendo, con él debería también admitirse su compatibilidad con sistemas injustos. El propio autor parece ponerlo de manifiesto, cuando señala que incluso las bandas de quienes cometen robos, requieren ciertas leyes que aseguren su existencia perversa,

\footnotetext{
119 Ibídem, p. 32.

${ }^{120}$ LAPORTA, F. J.; op. cit., p. 162; BOBBIO, N.; op. cit., p. 132.

${ }^{121}$ DE MARIANA, J.; La dignidad real ..., pp. 386 y 387.
}

así como equidad a la hora de dividir lo obtenido por la actividad desarrollada ${ }^{122}$.

Sin embargo, la postura del jesuita pensamos que va más allá. En su exposición sobre la justicia en general, aunque de forma muy colateral, identifica la supresión de la justicia con la destrucción de las virtudes ${ }^{123}$. Si tenemos en cuenta este detalle, cabría entender que las características de la ley no únicamente son valiosas por su contribución a los resultados anteriormente citados, sino también porque suponen una aportación a la consecución de la justicia material. Ello entendemos que se confirma, si detenemos la atención en lo que Mariana denomina "justicia legal”, que hace referencia a la obediencia a las leyes, sin la cual la sociedad no podría subsistir ${ }^{124}$, y que además "comprende todas las virtudes"125. Esta interpretación ${ }^{126}$ del texto del jesuita cobra fuerza, si tenemos en cuenta que a la hora de iniciar el desarrollo sobre las clases de justicia se apoya en "los grandes filósofos de la antigüedad"127, y que en la Ética a Nicómaco de Aristóteles (probablemente, una de sus fuentes en este

122 DE MARIANA, J.; La dignidad real..., p. 387; DE MARIANA, J.; Discurso..., p. 160.

123 DE MARIANA, J.; La dignidad real..., pp. 385, 386.

${ }^{124}$ Ibídem, p. 388.

${ }^{125}$ Ibídem, p. 388.

126 Entendemos que está presente en MARTÍNEZ-SICLUNA SEPÚLVEDA, C.; "La teoría del tiranicidio en Juan de Mariana", en Sánchez Garrido, P. y Martínez-Sicluna Sepúlveda, C. (eds.), Historia del análisis político, Madrid, Tecnos, 2011, p. 257.

${ }^{127}$ DE MARIANA, J.; La dignidad real ..., p. 387. 
punto), se hace referencia a la conveniencia común y a que las leyes ordenan lo que es propio de las virtudes ${ }^{128}$. Si aceptamos tal planteamiento, con él habremos de confirmar la idea de que las características de la ley son instrumentos que deben cuidarse, no ya únicamente porque suponen una aportación a la justicia formal, capaz de sustentar una comunidad, sino también porque son una contribución para la consecución de aquella justicia material que se recoge en el contenido de las leyes.

\section{El desarrollo expuesto parece enmarcar a Mariana} en el iusnaturalismo ontológico. La afirmación cobra fuerza si tenemos en cuenta la definición de ley que propone el autor ("Est enim lex ratio omni perturbatione vacua, à mẽte divina hausta, honesta \& salutaria praescribens, prohibẽsque contraria" ${ }^{129}$; es decir, la ley es la razón libre de toda perturbación, inspirada en la mente divina, que prescribe lo honorable y saludable y prohíbe lo contrario) y otras apreciaciones recogidas en el De rege $e^{130}$. Tal propuesta se confirma además en estudios que ven en la obra del jesuita un reflejo

\footnotetext{
128 ARISTÓTELES; Ética a Nicómaco, Araujo, M. y Marías, J. (trad.), Madrid, Centro de Estudios Constitucionales, 1985, p. 71.

${ }^{129}$ MARIANAE, I.; De rege..., p. 23. Sobre ello CENTENERA SÁNCHEZ-SECO, F.; El tiranicidio en los escritos de Juan de Mariana, Madrid, Dykinson, 2009, p. 319.

130 Así, por ejemplo, en el siguiente texto: “En las leyes está contenido lo que es lícito y justo, y el que las viola se aparta de la justicia y rectitud". DE MARIANA, J.; La dignidad real..., p. 107.
}

de la tesis tomista ${ }^{131}$. Es cierto, no obstante, que desde una interpretación en la línea de la filosofía agustiniana, podría decirse que el autor es pesimista en cuanto al logro de la justicia en la ley, a consecuencia de la condición humana ${ }^{132}$. Pueden localizarse textos del jesuita que ofrecen razones para pensar así, aunque también son posibles interpretaciones encontradas ${ }^{133}$. En todo caso, ello que no obsta para seguir enmarcando al autor en la concepción iusnaturalista, aunque sí cuestionaría su carácter ontológico ${ }^{134}$. Desde esta última perspectiva debería interpretarse que las

${ }^{131}$ NAVARRO AZNAR, F.; op. cit., pp. 327 y ss.; MARTÍNEZSICLUNA SEPÚLVEDA, C.; op. cit., pp. 251 y ss. Pensamos, no obstante, que podría ser también factible la opción que ve en las palabras de Mariana un reflejo de la filosofía agustiniana (véanse las referencias de la penúltima nota al pie de este trabajo). Desde una perspectiva mediata, probablemente deba verse como fuente a ARISTÓTELES; Política..., p. 104; para quien la defensa de la ley es la de la "divinidad y la razón", siendo aquella "razón sin apetito".

132 BRAUN, H. E.; “Juan de Mariana, la antropología política del agustinismo católico y la razón de Estado", Pérez Magallón, J. (trad.), Criticón, 118, 2013, pp. 102, 106, https://cvc.cervantes .es/literatura/criticon/PDF/118/118 099.pdf; BRAUN, H. E.; Juan de Mariana..., pp. 44, 59.

133 La cuestión daría lugar a otro estudio. Por lo que respecta a este, sirva el siguiente ejemplo. Como sabemos, el jesuita dice que "las leyes se establecen cuando se promulgan, y se aprueban cuando se confirman por las costumbres del pueblo" (DE MARIANA, J.; La dignidad real..., p. 95). Sin embargo, no parece que con ello esté reconociendo la posibilidad de que existan leyes injustas, sino la importancia de que se obedezcan a lo largo del tiempo por la fuerza que ello aporta (aspecto en el que, recordemos, podría verse un reflejo de ARISTÓTELES; Política..., p. 50). Por lo demás, Mariana reconoce como fuente en este punto Agustín de Hipona, que se enmarca en el iusnaturalismo ontológico. Puede verse, por ejemplo, SAN AGUSTÍN; "La Ciudad de Dios", Santamarta del Río S. y Fuertes Lanero, M. (trad.), en Obras completas de San Agustín, vol. XVII, Madrid, Biblioteca de Autores Cristianos, 1988, p. 608; SAN AGUSTÍN; "El libre albedrío", Seijas, E. (trad.), en Obras de San Agustín, vol. III, Madrid, Biblioteca de Autores Cristianos, 1982, p. 227.

${ }^{134}$ DUARTE SILVA, L.; op. cit., p. 106, repara en el detalle de que para Braun, Mariana toma la ley natural como referencia de las leyes justas. 
características que nos han venido ocupando suponen una contribución a la justicia formal, $y$ también a la material a la que deben tender las leyes, si bien esto último no tiene carácter necesario. 


\section{Bibliografía}

ANÓNIMO; Descripción de la Sinapia, península en la tierra austral, Madrid, Dykinson, 2013.

ASTARLOA, I.; (dir. y coord.), Memento práctico. Técnica Normativa, Madrid, Francis Lefebvre, 2015.

ANSUÁTEGUI ROIG, F. J.; Razón y voluntad en el Estado de Derecho. Un enfoque filosófico-jurídico, Madrid, Dykinson, 2013.

APOLODORO; Biblioteca Mitológica, García Moreno, J. (trad.), Madrid, Alianza Editorial, segunda reimpresión, 2013.

ARCOS RAMÍREZ, F.; La Seguridad Jurídica: Una Teoría Formal, Madrid, Dykinson, 2000.

ARISTÓTELES; Ética a Nicómaco, Araujo, M. y Marías, J. (trad.), Madrid, Centro de Estudios Constitucionales, 1985.

ARISTÓTELES; Política, Marías, J. y Araujo, M. (trad.), Madrid, Centro de Estudios Constitucionales, 2. ${ }^{a}$ edición, 1989.

BENTHAM, J.; Nomografía o el arte de redactar leyes, Pabón, C. (trad.), Madrid, Centro de Estudios Políticos y Constitucionales, 2004.

BENTHAM, J.; Tratados de legislación civil y penal, Rodríguez Gil, M. (ed.), Madrid, Editora Nacional, 1981.

BERMUDEZ DE PEDRAÇA, F.; Arte legal para estvdiar la Ivrisprvdencia, Salamanca, Emprenta de Antonia Ramirez, 1612.

BOBBIO, N.; Teoría general del derecho, Guerrero, R., J. (trad.), Bogotá, Temis, quinta reimpresión de la segunda edición, 2005.

BRAUN, H. E.; Juan de Mariana and Early Modern Spanish Political Thought, Hampshire, Ashgate, 2007.

BRAUN, H. E.; "Juan de Mariana, la antropología política del agustinismo católico y la razón de Estado", Pérez Magallón, J. (trad.), Criticón, 118, 2013, https://cvc.cervantes.es/literatura/criticon/PDF/118/118 099 .pdf.
CENTENERA SÁNCHEZ-SECO, F.; "De Toledo a Londres: el último viaje de Juan de Mariana", Cabeza encantada. Humanism e-review, 2011, http://www.proyectos.cchs.csic.es/humanismoyhumanistas/s ites/proyectos.cchs.csic.es.humanismoyhumanistas/files/CE NTENERA\%20DE\%20TOLEDO\%20A\%20LONDRES(2) 0.pdf.

CENTENERA SÁNCHEZ-SECO, F.; "El lenguaje de la ley humana en el pensamiento de Francisco Suárez", Pensamiento. Revista de Investigación e Información Filosófica, $74 / 279$,

2018 , http://revistas.upcomillas.es/index.php/pensamiento/article/ view/8789/8302.

CENTENERA SÁNCHEZ-SECO, F.; El tiranicidio en los escritos de Juan de Mariana, Madrid, Dykinson, 2009.

CENTENERA SÁNCHEZ-SECO, F.; "La cuestión del tiranicidio en Mariana y los reyes franceses del momento", Congreso Internacional la actualidad del padre Juan de Mariana (en prensa).

CENTENERA SÁNCHEZ-SECO, F.; "Los paradigmas de redacción normativa como medio para alcanzar la seguridad: ¿una apuesta segura?”, Ius Humani. Revista de Derecho, 3, 2012/2013, http://oaji.net/articles/2015/17061424886391.pdf.

CLÉRO, J. P.; "Bentham, crítico de la religión”, Torres Rosell, N. y Escamilla Castillo, M. (trad.), Anales de la Cátedra Francisco Suárez, 48, 2014, http://revistaseug.ugr.es/index.php/acfs/article/view/2784/2 $\underline{901 .}$

COUUARRUUIAS À LEYUA, D.; Vetervm Collatio Nvmismatvm, cum his, quae modò expenduntur, publica \& Regia authoritate percusa, Salmanticae, Excudebat Andreas à Portonarijs Typographus Regius, MDLXII.

DE MARIANA, J.; "Del rey y de la institución real”, en Pi y Margall, F. (ed.), Obras del padre Juan de Mariana, Madrid, M. Rivadeneyra, 1854.

DE MARIANA, J.; Discurso de las enfermedades de la Compañia, Madrid, Imprenta de D. Gabriel Ramirez, 1768. 
DE MARIANA, J.; La dignidad real y la educación del rey, Sánchez Agesta, L. (trad.), Madrid, Centro de Estudios Constitucionales, 1981.

DE MARIANA, J.; Tratado y discurso sobre la moneda de vellón, Madrid, Ministerio de Economía y Hacienda, 1987.

DE RIBADENEYRA, P.; Historia ecclesiastica del scisma del Reyno de Inglaterra, Madrid, En casa de Pedro Madrigal, 1588.

DE ROTTERDAM, E.; Elogio de la estupidez, Fanego Pérez, T. (ed.), Madrid, Akal, 2004.

DÍAZ, E.; Estado de Derecho y sociedad democrática, Madrid, Taurus, $4^{\mathrm{a}}$ edición, 2010.

DUARTE SILVA, L.; $O$ direito de resistência $e o$ tiranicidio no pensamento político de Juan de Mariana: contextualização, apresentação e a justificação do direito de resistência, Tesis Doctoral, Porto Alegre, 2017, http://tede2.pucrs.br/tede2/bitstream/tede/7539/2/TES

LUCAS DUARTE SILVA COMPLETO.pdf.

ENDICOTT, T.; Palabras y Reglas. Ensayos en filosofia del derecho, Navarro, P. (trad.), México, Distribuciones Fontamara, 2004.

EZQUERRA REVILLA, I. J.; Justicia y gobierno en el siglo XVI. El Consejo Real de Castilla durante el reinado de Felipe II (1556-1598), Tesis Doctoral, Madrid, Universidad Autónoma de Madrid, 1999, https://repositorio.uam.es/handle/10486/2583.

FERRERES COMELLA, V.; El principio de taxatividad en materia penal y el valor normativo de la jurisprudencia (Una perspectiva constitucional), Madrid, Civitas, 2002.

FULLER, L. L.; La moral del derecho, Navarro, F. (trad.), México, Trillas, 1967.

GARCÍA-GALlO, A.; Manual de Historia del Derecho Español, vol. I, Madrid, Artes Gráficas y Ediciones S. A., $9^{\text {a }}$ edición, 1982.

GARCÍA HERNÁN, E.; “Juan Luis Vives y Tomás Moro en la crisis religiosa del siglo XVI", en Betrán J. L., Hernández, B., Moreno, D. (eds.), Identidades y fronteras culturales en el mundo ibérico en la Edad Moderna, Barcelona, Universitat Autònoma de Barcelona, 2016.

HART, H. L. A.; El Concepto de Derecho, Carrió, G. R. (trad.), Buenos Aires, Abeledo-Perrot, segunda edición (reimpresión), 2004.

HIERRO, L. L.; "El imperio de la ley y la crisis de la ley",

Doxa,

19 ,

1996 ,

https://rua.ua.es/dspace/bitstream/10045/10482/1/doxa19__

5.pdf.

HORKHEIMER, M.; "La Utopía”, Equipo Editorial (trad.), en Muniesa, B. (selec. y present.), Sociología de la Utopía, Barcelona, Hacer, 1992.

LAPORTA, F. J.; El imperio de la ley. Una visión actual, Madrid, Trotta, 2007.

MARCILLA CÓRDOBA, G.; Racionalidad legislativa. Crisis de la ley y nueva ciencia de la legislación, Madrid, Centro de Estudios Políticos y Constitucionales, 2005.

MARIANAE, I.; De rege et regis institutione Libri III, Toleti, Apud Petrum Rodericum, 1599.

MARTÍNEZ-SICLUNA SEPÚLVEDA, C.; "La teoría del tiranicidio en Juan de Mariana", en Sánchez Garrido, P. y Martínez-Sicluna Sepúlveda, C. (eds.), Historia del análisis político, Madrid, Tecnos, 2011.

MORO, T.; Utopía, García Estébanez, E. (trad.), Madrid, Tecnos, 1987.

NAVARRO AZNAR, F.; "Trilogía de la ley en Juan de Mariana", en Bello, E. (ed.), Filosofía, sociedad e incomunicación. Homenaje a Antonio García Martínez, Murcia, Secretariado de Publicaciones. Universidad de Murcia, 1983.

ORTEGO GIL, P.; "El arbitrio de los jueces inferiores: su alcance y limitaciones”, en Sánchez-Arcilla Bernal, J. (inv. principal), El arbitrio judicial en el Antiguo Régimen (España e Indias, siglos XVI-XVIII), Madrid, Dykinson, 2012.

PALACIOS MARTÍN, B.; "La representación municipal en Cortes. Estudio de la figura del Procurador de Zaragoza a mediados del siglo XV', España Medieval, 7, 1985, 
http://revistas.ucm.es/index.php/ELEM/article/viewFile/EL EM8585221241A/24614.

PANORMITANI, A.; Commentaria In Tertiam Secundi Decretalium Libri Partem, Venetiis, [s. ed.], MDLXXI.

PECES-BARBA, G., SEGURA ORTEGA, M.; "La filosofía de los límites del poder”, en Peces-Barba Martínez, G. y Fernández García, E. (Dir.), Historia de los derechos fundamentales, tomo I, Madrid, Dykinson, 1998.

PÉREZ LUÑO, A.-E.; La seguridad jurídica, Barcelona, Ariel, 2. ${ }^{a}$ edición revisada y puesta al día, 1994.

PÉREZ MARTÍN, A.; "El Ius commune: artificio de juristas", en De Montagut, T. (ed.), Història del pensament jurídic, Barcelona, Universitat Pompeu Fabra, 1999.

PINO ABAD, M.; Persecución y castigo de la exportación ilegal de bienes en Castilla (siglos XIII-XVIII), Madrid, Dykinson, 2014.

POCH, A.; "Estudio preliminar", en Moro T.; Utopía, Madrid, Tecnos, 1987.

PRIETO SANCHÍS, L.; Ley, principios, derechos, Madrid, Dykinson, 1998.

Proceso Fabricado a instancia de Dn Gilimon de la Mota, Fiscal [...] contra el Padre Juan de Mariana de la Compañia de Jesus, manuscrito, 1610.

RAMIRO AVILÉS, M. A.; "Estudio introductorio", en Anónimo; Descripción de la Sinapia, península en la tierra austral, Madrid, Dykinson, 2013.

RAMIRO AVILÉS, M. A.; "La utopía del Derecho", Anuario de Filosofia del Derecho, 19, 2002, https://www.boe.es/publicaciones/anuarios derecho/abrir $p$ df.php?id=ANU-F-2002-10043100460.
SAN AGUSTÍN; "El libre albedrío", Seijas, E. (trad.), en Obras de San Agustín, vol. III, Madrid, Biblioteca de Autores Cristianos, 1982.

SAN AGUSTÍN; "La Ciudad de Dios", Santamarta del Río S. y Fuertes Lanero, M. (trad.), en Obras completas de San Agustín, vol. XVII, Madrid, Biblioteca de Autores Cristianos, 1988.

SARABIA VIEJO, M. J.; Don Luis de Velasco virrey de Nueva España. 1550-1564, Sevilla, Escuela de Estudios Hispano-Americanos, 1978.

SUÁREZ, F.; Tratado de las leyes y de Dios Legislador, vol. II, Eguillor Muniozguren, J. R. (trad.), Madrid, Instituto de Estudios Políticos, 1967.

SUÁREZ, F.; Tratado de las leyes y de Dios legislador, vol. III, Eguillor Muniozguren, J. R. (trad.), Madrid, Instituto de Estudios Políticos, 1968.

SUÁREZ LLANOS, L.; "Razón, política y legislación (I). El liberalismo político: redentor y verdugo del derecho", en Martínez Roldán, L., Fernández Suárez, J. A., Suárez Llanos, L.; La ley desmedida. Estudios de Legislación, Seguridad y Jurisdicción, Madrid, Dykinson, 2007.

ZAPATERO, V.; "Edición y estudio preliminar", en Bentham, J.; Nomografia o el arte de redactar leyes, Madrid, Centro de Estudios Políticos y Constitucionales, 2004.

ZAPATERO, V.; El Arte de Legislar, Pamplona, Aranzadi, 2009.

XANTHAKI, H.; Thorton's Legislative Drafting, Great Britain, Bloomsbury Professional, fifth edition, 2013. 